\title{
On Accelerating Medicines Partnership Initiative: Better Diagnosis without Better Therapies?
}

\author{
Karel Petrak* \\ NangioTx Inc, USA
}

Submission: August 14, 2017; Published: September 21, 2017

*Corresponding author: Karel Petrak, NangioTx Inc, 555 5th Avenue, New York, NY, USA 10017-9254, USA, Email: klpetrak@gmail.com

\begin{abstract}
Research strategy of the Accelerating Medicines Partnership is examined, with a conclusion that, in addition to identifying disease biomarkers, more effort should be put into identifying and developing molecular targets of disease.
\end{abstract}

\section{Failure of clinical trials}

Although the process of discovering, inventing new drugs is largely based on science, serendipity still plays an important part in its success. It has been reported that some $70 \%$ of Phase II trials do not reach their primary goals and thus are unsuccessful $[1,2]$. Failure of early-phase clinical trials may be expected since these are designed to explore whether the positive data obtained in preclinical studies in animals translate to human patients, and thus providing a proof of mechanism of action, a proof of concept [3]. One might expect that positive results of Phase II studies would often be reproduced in the subsequent Phase III studies that use a larger number, and a broader range of patients. However, an average of $50 \%$ of Phase III trials have been reported to fail $[1,2]$, with the rate varying according to indications.

According to NIH Director Dr. Collins, "the failure rate results largely from poor target selection and preclinical experiments in cell-based or animal models that do not properly represent human disease". However, let us not be too hasty in agreeing in Dr. Collins's view and assumption. Conditions of Phase II and Phase III trials are quite different. Phase II trials are performed on groups of 100-300 patients and are designed to assess whether the drug works in humans, and how safe it is. These studies are often performed in clinical-research environment. Phase III studies are randomized, controlled multicenter trials on large patient groups (300-3,000 and even more depending upon the disease) and aim to provide definitive data on how effective the drug is in a clinical setting, in comparison with current 'gold standard' treatment.

These are difficult trials to design and run, especially in therapies for chronic medical conditions. Phase III is not a re-run of Phase II, so different results are to be expected. Development of recombinant human lactoferrin (rhLF) can be used as a classic example. Phase II clinical study that evaluated efficacy of rhLF to treat severe sepsis produced "spectacular" results; 194 adults were treated within 24 hours of the onset of severe sepsis. The all-cause mortality at 28 days was $26.9 \%$ in the placebo group and $14.4 \%$ in the rhLF group (two-sided $\mathrm{p}=0.052$ ), representing a $12.5 \%$ absolute and a $46.5 \%$ relative reduction in mortality [4]. Subsequent Phase III clinical study, performed by a different company, using a larger number of patients and less stringent acceptance requirements, failed to reach its primary goal [5].

\section{Formation of Accelerating-Medicine Partnership}

Under Dr. Collins's direction, the NIH has set up in February 2014 a public-private partnership between the National Institutes of Health (NIH), the U.S. Food and Drug Administration (FDA), 10 biopharmaceutical companies and a number of non-profit organizations under the Accelerating Medicines Partnership (AMP) initiative [6]. In recent years, more than 1,000 new biological changes have been identified which might serve as biomarkers and drug targets. The Initiative plans to build on this, continue working in this general direction in order to develop new diagnostics and treatments by identifying new biological targets for diagnostics and therapeutics, and ultimately to reduce the time and cost of developing new and effective treatments. However, let us note that the initiative does not in any way address the issues responsible for the frequent failure of clinical studies.

By finding new biomarkers of diseases, AMP hopes to enable better characterization of disease early signs and administer 
treatments early. There is much basic and clinical science effort planned in AMP program, but not so much in the area of target development. On the rationale that "NIH is not a drug company", the development of new targets identified and validated by the AMP-sponsored projects will be expected to be taken up by pharmaceutical companies; development of new "precision drugs" will then require a major effort to make advanced therapies available to patients [7].

What has been achieved after 3 years of the program? For example, in the part of the AMP program performed by the National Institute of Arthritis and Musculoskeletal and Skin Diseases (NIAMS) and the National Institute of Allergy and Infectious Diseases (NIAID), as participating members of the AMP RA/SLE, Research Phase 0 has been completed, including establishing Network infrastructure, testing different means of obtaining and prepping tissue, developing standard operating procedures for preparation of synovial (joint) tissue for RA projects and kidney tissue for lupus projects, testing and validating cutting-edge technologies, such as CyTOF (Cytometry by Time of Flight) and RNA-seq (RNA sequencing) in synovial and kidney tissues, developing proposals for pilot projects to explore other emerging technologies and additional types of biological specimens, establishing clinical protocols and procedures for Phase I studies, and establishing systems for data management and analysis, including databases for clinical data and biospecimen tracking, and storage of experimental data, i.e., putting in place "preliminaries" [8].

In Research Phase I, standardized technologies established in Phase 0 to analyze samples from patients with RA and SLE were used. The Phase I results have provided information on the feasibility and design of larger studies to be carried out during Phase II. Discussion of the Phase I program that took place at the National Arthritis and Musculoskeletal and Skin Diseases Advisory Council meeting on June 21, 2017 is available for viewing [9].

\section{AMP and molecular targets of diseases}

The focus of AMP is clearly on disease diagnosis. This will be of very limited benefit to patients unless corresponding therapies are developed that are directed to, and act on molecular targets responsible for the initiation and progression of the disease.

In my series of articles published over time I discussed what is needed to be done to bring effective targeted, "precision drugs" to clinical practice [10-15]. One particular aspect is important when we discuss disease targets. "The term "targeted drugs" has been used broadly to describe drugs that act on general pathways that have been found to be associated with disease (but that also remains functional in normal cells), but it has also been used to refer to drugs approved for a selected and limited "target" population. In here, our interest focuses on drugs that interact specifically with a molecular structure, i.e., the drug's target that has been clearly identified and validated as being uniquely associated with a given disease; therapeutic antibodies are probably the best example of targeted drugs [10].
AMP has selected to work on the following diseases Alzheimer's, type-2 diabetes, rheumatoid arthritis (RA), and systemic lupus erythematosus (SLE). The focus is on observing how biological systems work, and leaving the task of developing new ways to correct aberrant behavior of the system with drugs to others, mainly pharmaceutical companies. In fact, development of new drugs does not need to wait for results produced by AMP. Taking type-2 diabetes as an example, pharmaceutical companies have enough material to start with Shi et al. [16] have given a broad overview of 14 prominent molecular targets that could be pursued in order to develop treatment of diabetes. These targets are roughly divided into general areas that correlate with insulin secretion, act on the insulin sensitivity, and have an effect on complications associated with diabetes. The authors believe that this provides drug developers with a "myriad of promising diabetes targets" for treating type- 2 diabetes. Similar situation exists in the other diseases that are the focus of the AMP.

\section{Conclusion}

A separate initiative focusing on converting validated targets of diseases into effective therapies is needed.

\section{References}

1. Stopke E (2015/2016) Burns J New drug and biologic R\&D success rates, 2004-2014. PAREXEL's Bio/Pharmaceutical R\&D Statistical Sourcebook.

2. Sacks LV, Shamsuddin HH, Yasinskaya YI, Bouri K, Lanthier ML, et al. (2014) Scientific and regulatory reasons for delay and denial of FDA approval of initial applications for new drugs, 2000-2012. JAMA 311(4): 378-384.

3. (1997) ICH Expert Working Group. General Considerations for Clinical Trials E8.

4. Guntupalli K, Dean N, Morris PE, Bandi V, Margolis B, et al. (2013) TLF LF-0801 Investigator Group. A phase 2 randomized, double-blind, placebo-controlled study of the safety and efficacy of talactoferrin in patients with severe sepsis. Crit Care Med 41(3): 706-716.

5. (2012) Agennix Stops Phase II/III Talactoferrin Study in Sepsis Due to Higher Death Rates.

6. https://www.nih.gov/research-training/accelerating-medicines-partnership-amp

1. 7https://www.nature.com/scibx/journal/v7/n8/full/scibx.2014.215. html

2. 8.https://www.niams.nih.gov/funding/Funded_Research/AMP_RA_ Lupus/default.asp

3. 9.https://videocast.nih.gov/summary.asp?Live $=23201 \& \mathrm{bhcp}=1$

4. 10 Petrak K (2017) Molecular Drug Targets and Drug Delivery. J Cancer Oncol 1(2).

5. 11.Petrak K (2015) Precision Medicine and Site-specific Drug Delivery. Advances in Cancer Research 3(3): 1-3.

6. 12.Petrak K (2013) Targeting Drug Delivery Systems: Promises, Promises, and More Promises...Let's Change the Paradigm. Chapter 8 in Recent Advances in Drug Delivery Research. In: Valerio Voliani (Ed.), Pharmacology - Research, Safety Testing and Regulation Series, Nova Science Publishers, USA, pp.167-180.

7. 13.Petrak K (2012) Targeted Drug Delivery--Quo Vadis? Drug Development Research 73(2): 59-65. 
8. 14.Petrak K (2005) Essential properties of drug-targeting delivery systems. Drug Discov Toda 10(23-24): 1667-1673.

9. 15. Petrak K (2015) Antibodies - The "Magic Bullets" for Drug Delivery? Int J Drug Dev \& Res 7: 26-28.

DOI: 10.19080/MABB.2017.02.555580
10. 16. Shi D, Luo J, Wang L, Xu Q (2017) The Hot and Potential Targets of Type 2 Diabetes Mellitus Treatment in Recent Decade. Curr Drug Targets.

11.

\section{Your next submission with Juniper Publishers} will reach you the below assets

- Quality Editorial service

- Swift Peer Review

- Reprints availability

- E-prints Service

- Manuscript Podcast for convenient understanding

- Global attainment for your research

- Manuscript accessibility in different formats

( Pdf, E-pub, Full Text, Audio)

- Unceasing customer service

Track the below URL for one-step submission https://juniperpublishers.com/online-submission.php 